\title{
Effect of Green Organizational Identity, Green Shared Vision, and Organizational Citizenship Behavior for the Environment on Green Product Development Performance
}

\author{
Tai-Wei Chang ${ }^{1, *}$, Fei-Fan Chen ${ }^{2} \odot$, Hua-Dong Luan ${ }^{3}$ and Yu-Shan Chen ${ }^{3}$ \\ 1 Graduate School of Resources Management and Decision Science College, \\ National Defense University, No. 70, Sec. 2, Zhongyang N. Rd., Beitou Dist., Taipei City 112, Taiwan \\ 2 Department of Business Administration, National ChengChi University, Taipei City 116, Taiwan; \\ chenfefangm@gmail.com \\ 3 Department of Business Administration, National Taipei University, New Taipei City 237, Taiwan; \\ f7896885@gmail.com (H.-D.L.); yushan@gm.ntpu.edu.tw (Y.-S.C.) \\ * Correspondence: allain1105@yahoo.com.tw; Tel.: +886-228-966-301 (ext. 604408)
}

Received: 11 October 2018; Accepted: 21 January 2019; Published: 24 January 2019

\begin{abstract}
This study extends the research literature by exploring the relations among green organizational identity (GOI), green shared vision (GSV), green product development performance (GPDP), and organizational citizenship behavior for the environment (OCBE). Hypotheses were tested through structural equation modeling from a sample of 475 valid questionnaire respondents. The two main findings were as follows: (1) Positive effects for GOI and GSV between OCBE and GPDP and (2) Positive effects of OCBE for GPDP. The results further indicate that the relations among the GOI, GSV, and GPDP were partially mediated by the OCBE; the results point that the OCBE acts as mediator between GOI, GSV, and GPDP. After further examining the collecting data, we found (3) the relationship between GOI and GPDP is completely mediated by OCBE and (4) the relationship between GSV and GPDP is partially mediated by OCBE. These findings indicate that OCBE is critical in the GPDP of companies. Therefore, companies must develop the GOI and GSV to strengthen their OCBE and intensify their GPDP.
\end{abstract}

Keywords: green organizational identity; green shared vision; organizational citizenship behavior for the environment; green product development performance

\section{Introduction}

The evolution, development, and practices of modern industries have left an indelible mark on the environment: this is considered a major global concern [1]. Several researchers (e.g., Chuang and Huang [2]) have indicated that environmental awareness has intensified, and, thus, companies are under considerable pressures to follow international treaties and accords, some of which are the Montreal Protocol (1987), United Nations Framework Convention on Climate Change (UNFCCC) (1992), European Union environmental directive (WEEE, ROHS, and EuP) (2003), and the Kyoto Protocol (2005) [2]. The specifications of international environmental treaties and regulations have increasingly become crucial and stringent, thus considerably affecting the business environment [3-6]. Today, in terms of commercial growth, being attentive toward environmental protection concerns and avoiding behavior that harms the society, economy, and environment [7] are essential. It means that we should focus on commercial development and concern the environmental protection at the same time. For reducing such pressures, the concept of environmental protection and management has infiltrated 
corporate management [1,8-12]. Because of increasing usage of green products (GPs) [2,13-15] and benefits of green management, several companies have started becoming attentive toward green product development (GPD) and production [1,10,15-17]. Therefore, GPs have a substantial effect on the sustainability goals of companies [18]. GPD manifestation is generally associated with the progress of GPs, green services, green processes, and green practices and is considered an original, innovative, and useful business indicator [19]. When companies develop, design, and produce GPs, integrating green management into GPD is essential [16,20]. Zhou et al. [21] proposed that when leaders and employees are matching in the field of management psychology can improve green product development performance (GPDP). It does not help GPDP unless it is further internalized into an organizational climate.

According to Erkut [22], the process of innovating concepts aims to create market segments and benefits through technological knowledge and corresponding marketing knowledge. The behavioral tendencies and decision-making processes are generated by cognitive patterns, which are the starting points of new knowledge generation [23]. Therefore, when the company achieves pattern recognition [23] through previous experiences and knowledge, it establishes a corporate green identity and green common vision and then interacts with market knowledge. It gains entrepreneurial advantages and generates market benefits.

Erkut and Kaya [24] indicated that innovativeness of corporate social responsibility activities for spreading awareness depends on the establishment of a firm and the type of corporate culture and character it implements. Such innovativeness requires knowledge on current and potential employees to create and maintain a competitive advantage. Therefore, companies must integrate the corporate and employees to use innovative knowledge for gaining competitive advantage. Based on the aforementioned observation, this study explored the green shared vision (GSV) of the company, green organization identity, and green organization citizenship behavior oriented by employees. Employee behavior is crucial among several elements contributing to the success of GPD. However, this behavior may not be cultivated by formal reward or performance assessment systems [25]; therefore, the behavior of staff members in the company is frequently considered a primary factor for the success of green organization development [25-30]. Voluntary actions by the staff members of the company to improve the green management-related measures are essential, which is termed green organizational citizenship behavior, and this behavior is not formally included in organizational system rewards [25,31,32]. Therefore, green organizational citizenship behavior is an approach through which a company achieves environmental management or plans GPD and production.

Corporate GPD has received considerable attention because people are gradually learning about environmental preservation concerns $[16,33]$. The increasing consumer environmental awareness is responded to by developing environment-friendly products and services, which is crucial for successful businesses [20,34,35]. Although studies have broadly discussed concerns regarding GPDP, the research examining the effect of green organizational identity (GOI) and GSV on GPDP has been insufficient. However, GOI and green common vision are not mind acts upon mind, thus contributing to GPDP [21]. Therefore, the current study aimed to bridge this research different by proposing a research framework with four new constructs, namely the GOI, green common vision, organizational citizenship behavior for the environment (OCBE), and GPDP. Because GPD is becoming more significant for companies in this environmentalist period, a research framework comprising primary factors-such as the GOI, green common vision, and OCBE-to improve the GPDP of companies. Chen $[10,19]$ introduced the concept of the GOI, bot no study has investigated the impact of the GOI on OCBE. However, according to Maxfield [36], employees rely on previous cognition, knowledge, ideas, social participation, coordination, and interaction and mutual learning, which is endogenous because of organizational knowledge. The promotion of unique entrepreneurship and innovative practices and company resources help gain the competitive advantage of enterprises. Social participation and employee cognition are considered primary factors. For alleviating the research differences, a whole context-organizational action-outcome structure was developed. By examining 
the positive relation of the GOI on green innovation performance and discussing the influence of environmental commitment and environmental organizational legitimacy.

In this study, numerous research steps were followed. A literature survey on the GOI, green common vision, OCBE, and GPDP was conducted. Furthermore, the results were obtained from an empirical test to validate the relations among these curial variables. In particular, five hypotheses based on the study framework were proposed and tested. Finally, conclusions were derived, and the findings, implications, and future research were discussed in brief.

\section{Literature Review and Hypothesis Development}

\subsection{Positive Effect of GOI on OCBE}

Organizational identity can not only influence actions of staff members the company but also provide a frame of reference to guide managerial interpretations of strategic concerns $[37,38]$. Furthermore, the leadership of high-ranking managers and executives promulgates the interpretation of organizational behavior and creates faith, which directly influences the formation of organizational identity [39]. However, organizational identity depends on the understanding of the connection between responsibilities and tasks of company members with companies, thus intra-organizational green management is essential when environmental concerns are crucial components of organizational identity. The GOI is an interpretive scheme for environmental management and protection, which is collectively construct by members to provide meaning to their behaviors [10]. Organizational identity can shape the organization's strategies and actions, thus affecting the employees' behavior $[38,40]$. Since the environmental issues become more important, developing GOI can push the managers and employees to establish environmental awareness and green management. Finally, this helps firms to increase their green performance.

Geraie and Rad [41] proposed that, in the current turbulent environment, green identity organization are the source of innovation and can help maintain the competitive edge of the company. The corporate green identity can increase the number of innovative activities and improve the quality of the organizational success in a competitive business environment. Geraie and Rad [41] showed a significant correlation between total quality management and innovation with a sustainable competitive advantage, which is mediated by the GOI. The promotion of the GOI with positive environmental results as a standard framework within communities improves not only the company's quality and services but also employees' wellbeing, which subsequently provides a sustainable competitive advantage. When environmental concerns are incorporated into the organizational identity of the company, their positive impact is apparent and further inspires other staff members to commit to environmental activities [42]. In this way, the identification of green organizations with the role of an interpretive framework for green issues shows that the organization's green strategy often derives from the interpretation and management of environmental issues, and the strategy is often affected by organizational factors such as the legalization of environmental issues [10]. Numerous studies have revealed that organizational identification is significantly related to various attitudes (e.g., job satisfaction, job involvement, and affective organizational commitment) and behaviors (e.g., inrole and extrarole performance in organizations) $[43,44]$. In addition, previous studies on the organizational identity and organizational citizenship behavior have indicated a significant positive impact [43-48]. According to an organizational identity theory, in terms of environmental management, the GOI is an instrumental factor within an organization context. Moreover, Erkut [49] validated business conceptions of Witt [50] in the rise of the enterprise resource planning (ERP) software market, which is also in line with the rise of the ERP software market. Business conceptions are the process of identification and knowledge formation, which is guided by the cognitive frames of entrepreneurs and is subjective and heterogeneous. In this study, the formation of two variables, green organization identity and GSV, were led by entrepreneurs. These factors are subjective and heterogeneous and facilitate the imported member behavior and performance in organizations. These are positive effects 
for GOI on organizational actions regarding OCBE, which subsequently has a positive influence GPDP. For environmental protection, OCBE is the basis of green behavior. As stated by the aforementioned argument, the GOI is positively related to OCBE, thus we posit the following hypothesis:

Hypothesis $\mathbf{1}\left(\mathbf{H}_{\mathbf{1}}\right)$. GOI is positively related to OCBE.

\subsection{Positive Effect of GOI on GPDP}

Organizational identity has an evident impact on the attitude and effectiveness of organizational staff members [51], who adopt a high organizational identity following cooperative behavior, which can enhance the competitiveness of an organization [52]. Moreover, Cheny [53] indicated that organizational identity is related to organizational motivation, job performance, and organizational goals. First, Lee et al. [44] found that organizational identification is significantly associated with the three primary attitudes of job involvement, job satisfaction, and effective organizational commitment, with inrole and extrarole performances in organizations. Second, organizational identification is described using the classic psychological model of attitude-behavior relations [54] as a base for emerging general sets of attitudes and behaviors. In particular, organizational identification directly affects general behavior and general attitude. Because of the increasing pressures on environmental awareness and regulations, several global corporations have adopted GPD as a primary strategy. Chen [10] indicated the importance of the new concept of environmental management (i.e., GOI) to stimulate green innovation and use current environmental movements. The GOI is an essential construct focusing on environmental protection and management. Furthermore, GOI is totally created by the staff members of the organization and thus provides significance to their actions and behaviors. Furthermore, Chen [10] revealed the positive association between a GOI of the organization and its green competitive advantages. The existence of a positive and mediating effect for GOI among environmental organizational culture, environmental leadership, and green competitive advantage. The companies have to enhance their GOI by strengthening their environmental organizational culture and environmental leadership since they want to augment their green competitive advantage.

GPDP is defined as the development performance of products is less hurtful to the environment and is less dangerous to human health. In addition, GPDP is in part or whole made by using recycled components, energy-conservative methods, and supplied with less packaging to the market (Chang and Chen) [54]. Research has shown that GOI positively affects green innovation performance [55]. The empirical results by Chang [56] show that corporate environmental commitment positively affects GP innovation performance directly and positively influences it indirectly via green adaptive ability. Managers must realize that green innovation is integral to sustainable development and can confer a competitive advantage. Song and Yu [57] found that a green innovation strategy has a positive influence on the GOI and green creativity. Moreover, positive relations are observed between the GOI and green creativity and between green creativity and green innovation. Based on these findings, Song and $\mathrm{Yu}$ [57] urged managers to focus on finding methods to develop a sense of green identity in their organization and to stimulate green creativity, thus bolstering the ability of the organization for sustainable development. Similarly, Brown and Eisenhardt [58] identified that product development was a valuable capital of the organization to maintain competitive advantage and mentioned that corporations must be able to diversify in a continuous changing market and reshape their impression. Krishnan and Ulrich [59] hold the opinion that product development transforms market opportunities into services or products that satisfy consumers or other interested parties. However, integrating environmental concerns with product development is difficult when simultaneously complying with environmental regulations and market demands. According to organizational identity theory, the GOI is a major factor in environmental management and its interpretive context of an organization. Furthermore, the positive effects for GOI on organizational actions (i.e., OCBE), which subsequently has a positive effect on the outcome of GPDP. 
With the integration of power in organizational identity, organization staff members may be pleased that other members in the same green infrastructure agreed to proactively undertake environmental initiatives, such as spreading awareness on environmental concerns, creating an environment that explores the link between new technology and consumer demands, and enhancing innovation using significant and creative methods [60], and applying these initiatives to the development of new products. Therefore, the GOI is positively related to GPDP, which leads to the following hypothesis:

Hypothesis $\mathbf{2}\left(\mathbf{H}_{\mathbf{2}} \mathbf{)}\right.$. GOI is positively related to GPDP.

\subsection{Positive Effect of GSV on OCBE}

Bass [61] observed that a GSV provides appropriate guidelines and ideal goals for members of the organization, and thus, they can successfully overcome the current challenges and perform work-related tasks. Rice et al. [62] indicated that a shared vision can convey common insights, visions, knowledge, and blueprints for future ideals of members, and a shared vision can offer a common strategic direction to facilitate and reveal convergent goals [63]. Moreover, a shared vision uses potential for corporate success as a basis for visionary strategies [64]. Similarly, Giordan [65] stated that establishing a shared vision can be the basis for gaining a competitive advantage. A shared vision can assist staff members to perceive their work through a large and mindful context [66]. Furthermore, it can be used to motivate members of the organization to intensify their willingness to exceed expectations [67]. In summary, a shared vision can help senior members achieve numerous goals, such as establishing a common blueprint for future development, promulgating norms and values, motivating them to surpass performance expectations, and acting as a resource to develop future strategies.

The current study was drawn on a new concept proposed by Chen et al. [14] of GSV, which is based on the notions of environmental friendliness and sustainable development. When developing the future policies of the organization, the management should construct a shared platform to achieve the strategic goal of environmental protection - the strategic direction of the corporate goal of protecting the target. Chen et al. [14] The study proposed an original concept termed GSV, which is defined as a clear and common strategic direction for achieving collective environmental goals and aspirations that have been internalized by staff members of an organization. Katz and Kahn [68] proposed a role behavior theory, wherein job performance comprises two types of behaviors, namely inrole behavior and extrarole behavior. Furthermore, MacKenzie et al. [69] divided work performance into two behavioral categories, namely withinrole and extrarole behaviors. The withinrole behavior refers to outputs, which are formally required by the organization (i.e., regulated activities within the system. The extrarole behavior in the achievement of organizational goals is the behavior of staff members, who are willing to initiate and execute requirements beyond their job requirements and to enact or propose useful behavior, which can help the organization achieve its goals. In this study, the primary significance of OCBE is the same as that in the green organizational behavior. A shared vision provides a collective strategic direction, which can guide actions of members using a particular approach [70]. This study proposed a GSV and referred to Larwood et al. [70] and Chen et al. [14] as antecedents. A shared vision regarding green management is crucial for enhancing OCBE. The GSV is accordingly associated with OCBE, and the following hypothesis can be proposed:

Hypothesis $3\left(\mathbf{H}_{\mathbf{3}}\right)$. GSV is positively related to OCBE.

\subsection{Positive Effect of GSV on GPDP}

Product development is a vital bridge connecting organizations, markets, and the foundation of successful businesses [71]. The strategic management of product development is necessary for competitiveness in the market. The ineffective management of product development generates a 
competitive disadvantage and unstable future [72]. Furthermore, the development of GPs (either through product differentiation or low-cost production) probably confers competitive advantage [73]. Dangelico [18] explored the market performance of GPs, which focuses on motivations and characteristics of corporations. The result indicated that market benefits, availability of new technologies, foreign ownership of organizations, innovative products, and differentiation of products have a positive influence. This study further explored GPDP through an integrated perspective with a shared vision. The characteristics of the vision are the same as the characteristics, motivations, and objectives of the organization. Therefore, the vision promotes the GPDP of the organization. A shared vision can help staff members see their work through a large and mindful context [66]. As mentioned previously, a shared vision can be further used to motivate organizational staff members for increasing their willingness to perform beyond expectations [67], and therefore, in the field of environmental protection, the GSV for the environment is essential for cultivating the process of developing GPs. The aforementioned observations indicate that the GSV is associated with GPDP, and the following hypothesis can be proposed:

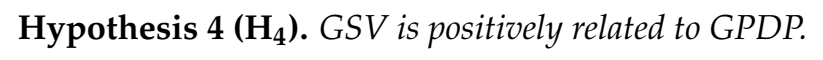

\subsection{Positive Effect of OCBE on GPDP}

Numerous previous studies have indicated that organizational citizenship behavior has a significant positive impact on organizational performance [74-76]. Consequently, green organizational citizenship behavior is positively relevant to GPDP. Scholars combined organizational citizenship with environmental protection because of the growth of environmentalism, which is termed green organizational citizenship behavior. Such spontaneous employee behavior is not directly regulated by the reward of the organization and the performance evaluation system; however, it can directly improve the environment [25]. OCBE identified in the study is related to employee contributions to the environmental initiatives by the organization, such as participation in environmental events, promotion of the organization green identity, and voluntary involvement in events regarding the proenvironmental practices of the organization [77]. Proenvironmental behaviors in the workplace are critical to degrade pollution at the source because of the development of preventive approaches [22,78]. The willingness of staff members of the organization to perform proenvironmental actions, such as OCBE, has been recognized as a primary factor for the success of environmental management activities [79]. Developing lean and green practices by staff members is crucial when improving production operations and environmental performance [80,81]. This study proposed that organizations concerned about environmental protection cannot act without the support of their staff members. Therefore, OCBE can considered a means to reach an environmental objective. Therefore, OCBE has positive effect on GPDP. According to the aforementioned explanation, we proposed the following hypothesis:

Hypothesis $\mathbf{5}\left(\mathbf{H}_{\mathbf{5}}\right)$. OCBE is positively related to GPDP.

According to the foregoing hypotheses and related research, we concluded the research framework, include effect of GOI, GSV, OCBE, and GPDP (Figure 1). 


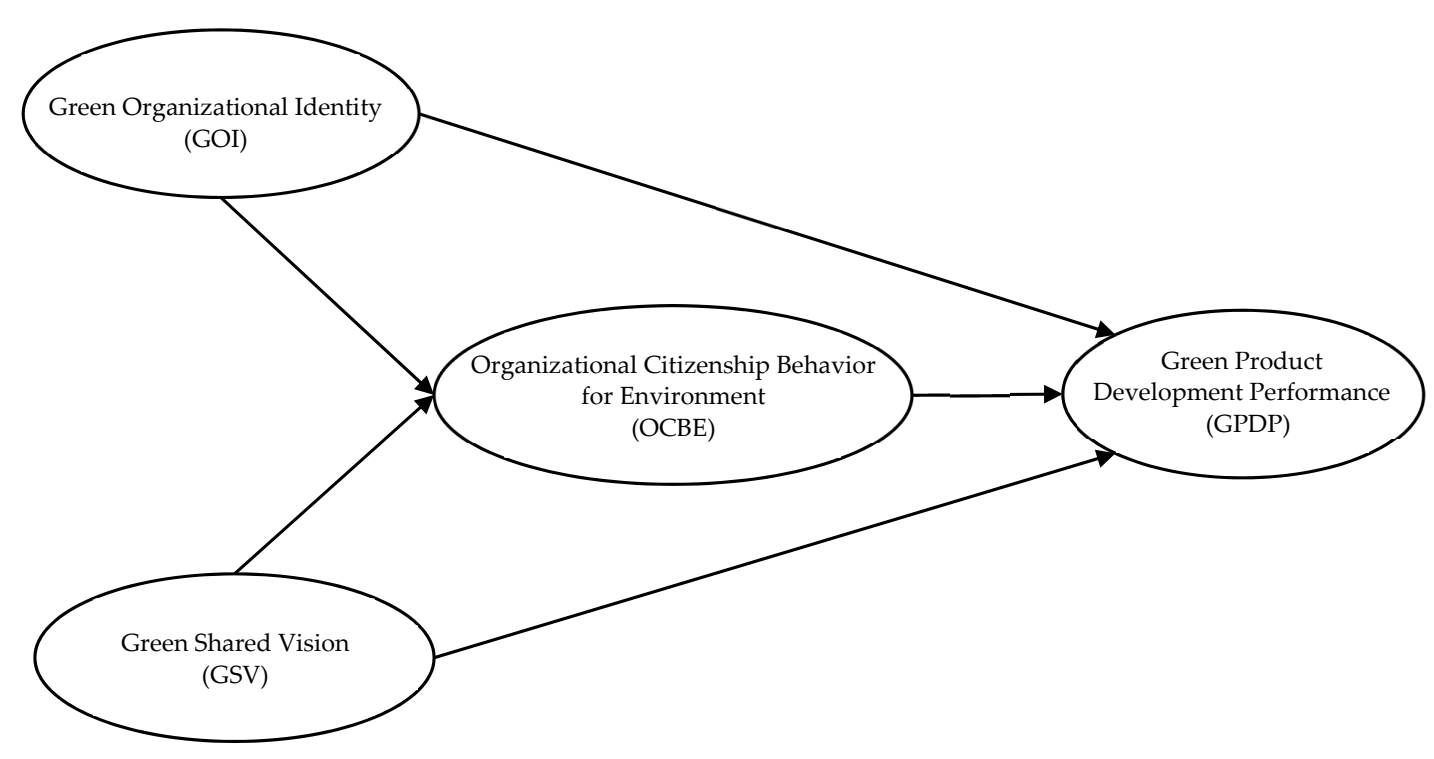

Figure 1. Research framework.

\section{Methodology and Measurement}

\subsection{Data Collection and Sample}

Data from a questionnaire were used to verify the aforementioned four hypotheses for Taiwanese manufacturing. The questionnaires were obtained by post during 1 April 2018, to 31 August 2018, and the informants were staff members in the following types of Taiwanese companies randomly selected from Taiwan business directory for several industries, including electronics, information services, components manufacturing, computer and peripheral products, electronic products and components, software industries, machinery and equipment manufacturing, biotech and health care, and communication equipment manufacturing. The respondents included chief executive officers (CEOs), managers of various departments (e.g., manufacturing, environmental, research and development, and marketing), and leaders and staff members of GPD projects. To provide details on the research purposes, including the contents of the questionnaire; and to ensure that participants were to receive a small gift; to ensure a higher response rate, each organization was contacted to validate the job titles and names of the participants. To ensure the content validity of the study, two rounds of pretests were conducted.

In accordance with Podsakoff and Organ [82], Podsakoff et al. [83] proposed that the problem of common method variance can be eliminated by collecting data from different interviewed sources and anonymity and confidentiality of the respondents to be employed in a prestudy phase. The respondents belonged to different industries and departments, thereby mitigating common method variance. Before sending the questionnaire to the organization, the contact was first asked whether the organization is developing or has developed GPs. The questionnaires were sent to the organization primarily for the promotion of sales products. The questionnaire respondents (i.e., all staff members of GPD projects) were asked to select a GPD project and answer questions regarding the following aspects: (1) the GOI, (2) GSV, (3) OCBE, and (4) GPDP of the project team. Nonmanagerial respondents answered questions regarding the first three aspects, whereas CEOs, managers, and assistant managers answered questions regarding GPDP. In summary, 770 formal questionnaires were sent, and 475 valid questionnaires were returned, with an effective response rate of $61.68 \%$. The results indicate the following industrial distribution: electronics $9.47 \%$ (45), information services $10.53 \%$ (50), components manufacturing $12.63 \%(60)$, computer and peripheral products $16.84 \%(80)$, electronic products and components $13.26 \%$ (63), communication equipment manufacturing 5.05\% (24), biotech and health care $6.32 \%(30)$, machinery and equipment manufacturing $4.21 \%$ (20), software industries $6.32 \%$ (30), among others $15.37 \%$ (73). The number of staff members are as follows: $30.11 \%(143)$ less than 100 people, $32.63 \%(155)$ 
$100-500,25.26 \%$ (120) 500-1000, and only $12 \%$ (57) more than 1000 people (see Table 1 ). These numbers indicate that the sample used in this study was primarily suitable small- and medium-sized enterprises.

Table 1. Sample distribution by industry classification.

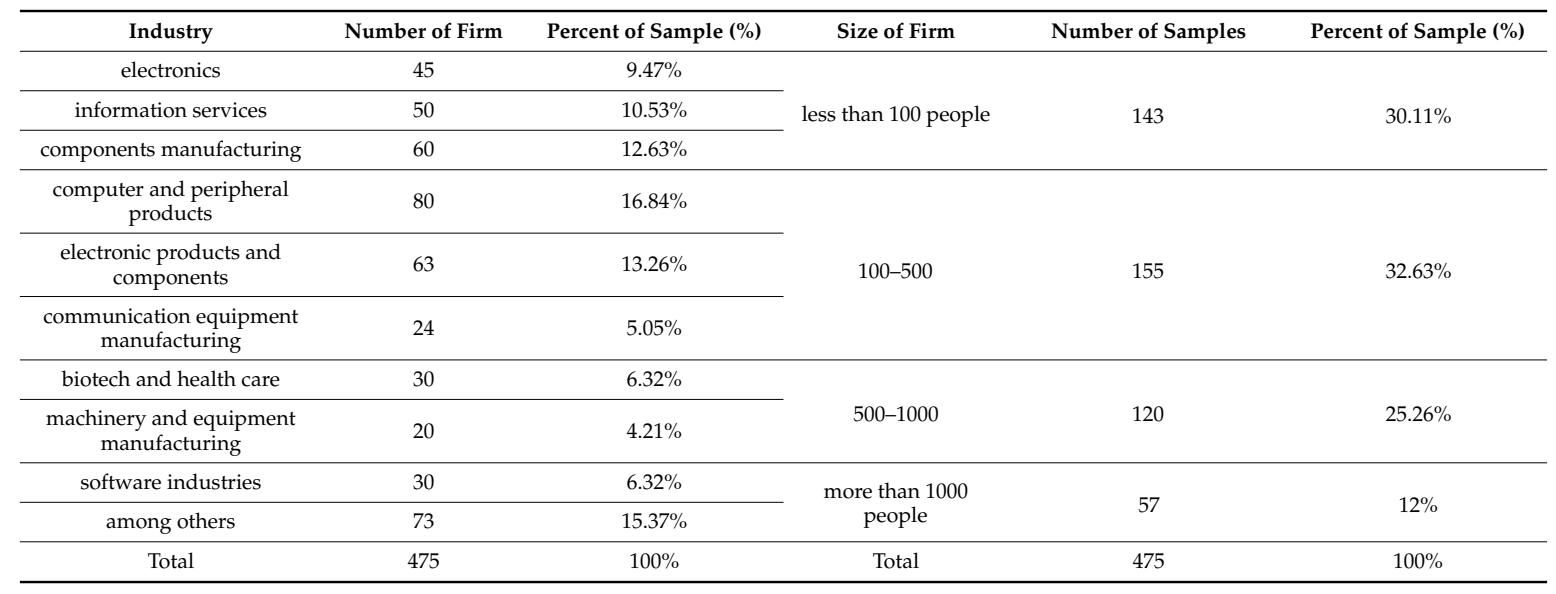

\subsection{Definitions and Measurements of Constructs}

The questionnaire in this study comprised four construct measurements of the GOI, GSV, OCBE, and GPDP. It was a "tick the box" survey.

\subsubsection{Green Organizational Identity (GOI)}

In this study, Chen's [10] six items on the development of the GOI were adopted (on a seven-point Likert scale from 1 (never) to 7 (frequently)), emphasizing that the GOI was related to mental or physical shared vision characteristics. The reliability of the items on the survey was 0.936 . The six questionnaire items are follows:

(1) top managers, middle managers, and employees of the organization are proud of its history regarding environmental management and protection; (2) top managers, middle managers, and employees of the organization are proud of its environmental objectives and missions; (3) top managers, middle managers, and employees think that the organization has maintained a significant position for environmental management and protection; (4) top managers, middle managers, and employees of the organization think that the organization has formulated well-defined environmental objectives and missions; (5) top managers, middle managers, and employees of the organization are knowledgeable about its environmental tradition and culture; and (6) top managers, middle managers, and employees of the organization identify that it provides considerable attention to environmental management and protection [10].

\subsubsection{Green Shared Vision (GSV)}

Following Chen et al. [14], the questionnaire in this study describes the development of the GSV by using four items (with the same seven-point Likert scale) to measure readability of the GSV with mental or physical shared vision characteristics. The reliability of the items was 0.897 . The items were as follows:

(1) A commonality of environmental goals exists in the company; (2) A total agreement on the strategic environmental direction of the organization; (3) All members in the organization are committed to the environmental strategies; and (4) Employees of the organization are enthusiastic about the collective environmental mission of the organization [14].

\subsubsection{Organizational Citizenship Behavior for Environment (OCBE)}

For the development of OCBE section of the survey, the ten items (with the aforementioned seven-point Likert scale) from Paillé et al. [84] were used and considered to be related to mental or 
physical shared vision characteristics. These items had a reliability of 0.964 . The following items were included: The following items were included:

(1) During work, I weigh my actions before doing something that could affect the environment; (2) I voluntarily conduct environmental actions and initiatives in my daily activities at work; (3) I make suggestions to my colleagues about ways to effectively protect the environment, even when it is not my direct responsibility; (4) I actively participate in environmental events organized in and/or by the organization; (5) I stay informed about my environmental initiatives of the organization; (6) I undertake environmental actions that contribute positively to the image of my organization; (7) I volunteer for projects, endeavors, or events that address environmental concerns in my organization; (8) I spontaneously give my time to help my colleagues take the environment into account in their actions at work; (9) I encourage my colleagues to adopt environmentally conscious behavior; and (10) I encourage my colleagues to express their ideas and opinions on environmental concerns [84].

\subsubsection{Green Product Development Performance (GPDP)}

In this study, ten items from Chen and Chang [19] (with the aforementioned seven-point Likert scale) to target the extent of the successful performance of GPD. The items had a reliability of 0.888 . The items were as follows:

(1) The project of GPD contributes significant revenues to the organization; (2) the project invents outstanding GPs; (3) the project continues to improve its development processes over time; (4) the project is more creative in GPD than its competitors'; and (5) the project can achieve its aims in GPD [19].

\section{Empirical Results}

\subsection{Measurement Model Results}

Table 2 presents the means, standard deviation, and positive correlations of the research framework. Table 3 provides details from the factor analysis and indicates that each constituent item is described in terms of the accumulated percentage of variance as explained by one factor. As for the pretests conducted to evaluate the content validity of the measurement. Table 4 presents statistically significant factor loadings $(\lambda)$ of all four constructs, thus indicating that the measurement model has satisfactory quality. In addition, Table 4 presents the Cronbach's $\alpha$, which are higher than 0.7 , thus providing acceptable reliability [85].

Measuring discriminant validity by using the average variance extracted (AVE) on the authority of Fornell and Larcker [86]. To satisfy the requirements of standard discriminant validity, the AVE square root of each construct should be higher than correlation coefficients among the constructs. For the GOI and GPDP, the square root of their AVEs were 0.842 and 0.764 , respectively, which were higher than their correlation of 0.646 , indicating their discriminant validity. Because Table 4 indicates that the square roots of all AVEs of all constructs are higher than the correlations of all the constructs in Table 2, the results can claim to have discriminant validity. Furthermore, AVE constructs are higher than 0.5, indicating convergent validity, and the four constructs have convergent validity because their AVEs are all higher than $0.5(0.71,0.689,0.7$, and 0.583$)$. The aforementioned results indicate that measuring instruments used in this have acceptable reliability and validity.

Table 2. Means, standard deviations, and correlations of the constructs.

\begin{tabular}{ccccccc}
\hline Constructs & Mean & Standard Deviation & A & B & C & D \\
\hline A. GOI & 5 & 0.8199 & 0.842 & & & \\
B. GSV & 5.167 & 1.0309 & $0.380^{* *}$ & 0.83 & & \\
C. OCBE & 4.6 & 1.037 & $0.547^{* *}$ & $0.629^{* *}$ & $0.837^{* *}$ & \\
D. GPDP & 5 & 0.699 & $0.646^{* *}$ & $0.471^{* *}$ & $0.637^{* *}$ & 0.764 \\
\hline
\end{tabular}

Note: Diagonal elements are the square roots of AVE, ${ }^{*}: p<0.05,{ }^{* *}: p<0.01$. 
Table 3. Factor analysis of this study.

\begin{tabular}{cccc}
\hline Constructs & Number of Items & Number of Factors & Accumulation Percentage of Explained Variance \\
\hline GOI & 6 & 1 & $76.438 \%$ \\
GSV & 4 & 1 & $75.776 \%$ \\
OCBE & 10 & 1 & $75.825 \%$ \\
GPDP & 5 & 1 & $69.255 \%$ \\
\hline
\end{tabular}

Note: green organizational identity (GOI); green shared vision (GSV); organizational citizenship behavior for the environment (OCBE); green product development performance (GPDP).

Table 4. Items' loadings $(\lambda)$ and constructs' Cronbach's $\alpha$ coefficients and AVEs.

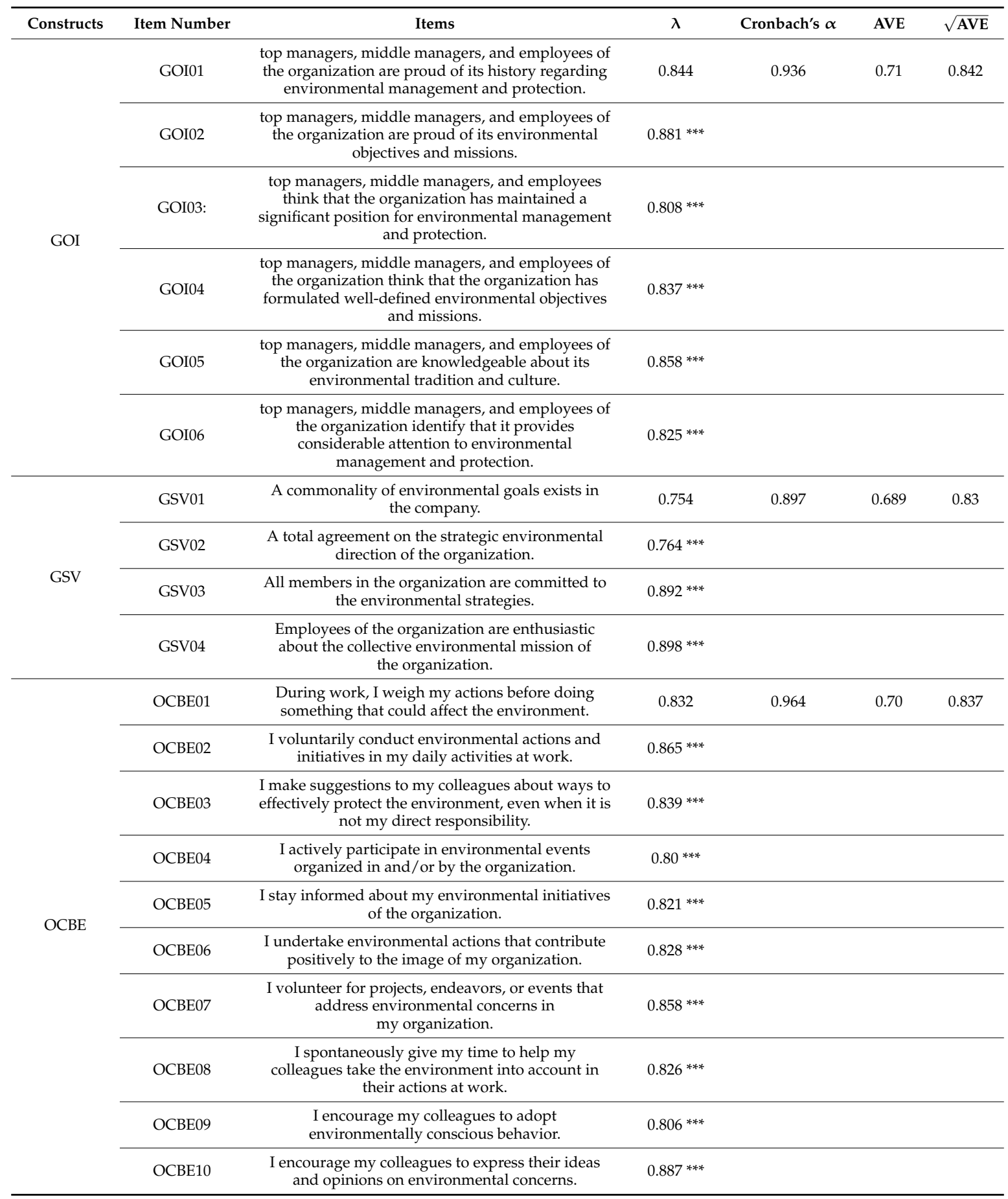


Table 4. Cont

\begin{tabular}{|c|c|c|c|c|c|c|}
\hline Constructs & Item Number & Items & $\lambda$ & Cronbach's $\alpha$ & AVE & $\sqrt{\mathrm{AVE}}$ \\
\hline \multirow{4}{*}{ GPDP } & GPDP01 & $\begin{array}{l}\text { The project of GPD contributes significant revenues } \\
\text { to the organization. }\end{array}$ & 0.77 & 0.888 & 0.583 & 0.764 \\
\hline & GPDP03 & $\begin{array}{l}\text { the project continues to improve its development } \\
\text { processes over time. }\end{array}$ & $0.801 * * *$ & & & \\
\hline & GPDP04 & $\begin{array}{l}\text { The project is more creative in GPD than } \\
\text { its competitors. }\end{array}$ & $0.74^{* * *}$ & & & \\
\hline & GPDP05 & The project can achieve its aims in GPD. & $0.739 * * *$ & & & \\
\hline
\end{tabular}

\subsection{Structural Model Results}

The hypotheses were tested using structural equation modeling and analysis of moment structure. Table 5 summarized the results, which present the acceptable fit of the full model (GFI $=0.874$, RMSEA $=0.067, \mathrm{NFI}=0.922$, and CFI $=0.946$ ). Figure 2 presents the results of the complete model . All five paths have significantly positive estimations, indicating that $\mathrm{H}_{1}, \mathrm{H}_{2}, \mathrm{H}_{3}, \mathrm{H}_{4}$, and $\mathrm{H}_{5}$ were validated in this study. An increase in the GOI and GSV can improve OCBE and GPDP. The GOI and GSV are crucial drivers of GPDP. Furthermore, the study validated that the positive relations among GPDP, GOI and GSV are partially mediated by OCBE. This validation indicates that the direct and positive effects of GOI and GSV on GPDP. In addition, the indirect and positive influence of OCBE on GPDP. The mediation effect test of Baron and Kenny [87] indicated that the OCBE mediates the relations between GOI, GSV, and GPDP. In this framework, antecedents are the GOI, GSV and reactive feedback. GPDP provides the results, and the mediator is OCBE (Figure 2). Therefore, organizations must improve their GOI, GSV, and OCBE for improving their GDPD.

Table 5. Results of structural model.

\begin{tabular}{cccc}
\hline Hypothesis & Proposed Effect & Path Coefficient & Results \\
\hline H1 & + & $0.396^{* * *}$ & $\mathrm{H}_{1}$ is supported \\
$\mathrm{H} 2$ & + & $0.488^{* * *}$ & $\mathrm{H}_{2}$ is supported \\
$\mathrm{H} 3$ & + & $0.581^{* * *}$ & $\mathrm{H}_{3}$ is supported \\
$\mathrm{H} 4$ & + & $0.113^{*}$ & $\mathrm{H}_{4}$ is supported \\
$\mathrm{H} 5$ & + & $0.356^{* * *}$ & $\mathrm{H}_{5}$ is supported \\
\hline \multicolumn{4}{c}{}
\end{tabular}

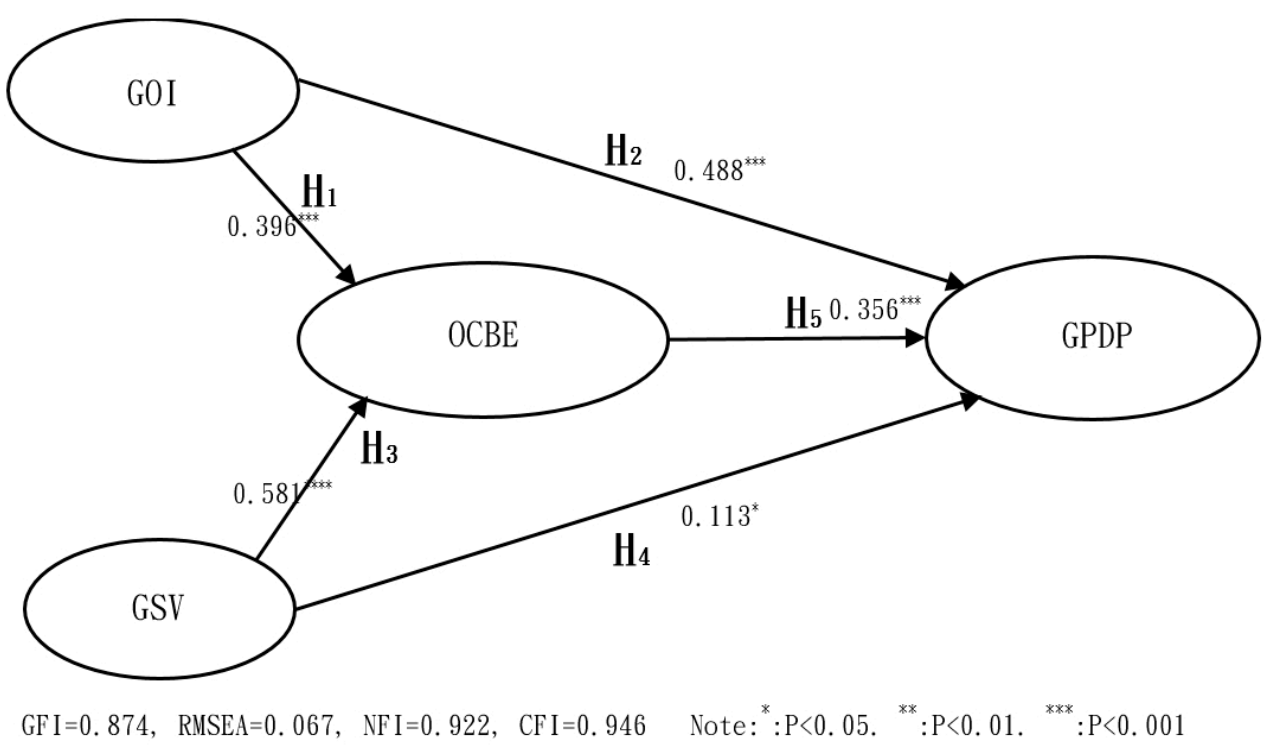

Figure 2. Full model results. 
Furthermore, in order to further examining the mediation role of OCBE, we executed percentile bootstrapping and bias-corrected percentile bootstrapping at a $99 \%$ confidence interval with 5000 bootstrap samples (Taylor et al. [88]). The results of the direct effects of GOI on OCBE (standardized direct effect 0.396, $\mathrm{p}<0.001$, see Figure 2), the direct effect of GOI on GPDP (standardized direct effect $0.488, p<0.001$, see Figure 2), the direct effect of GSV on OCBE (standardized direct effect 0.581, p $<0.001$, see Figure 2), the direct effect of GSV on GPDP (standardized direct effect $0.113, \mathrm{p}<0.005$, see Figure 2), and the direct effect of OCBE on GPDP (standardized direct effect 0.356 , $\mathrm{p}<0.001$ ) were all statistically significant. For the purpose of further investigating the indirect effects of the dependent variable through the mediators. As shown in Table 6, the results of the bootstrap test confirmed the existence of a positive and significant mediating effect for OCBE between GOI and GPDP (standardized indirect effect $0.207, Z>2.58$ ), and positive and significant mediating effects for OCBE between GSV and GPDP (standardized indirect effect 0.141, $Z>3.29$ ). We found that GOI was not strongly direct effect on OCBE (standardized direct effect $0.113, \mathrm{Z}<1.96$, a $95 \%$ percentile bootstrap of -0.114 to 0.107 , a $95 \%$ bias-corrected percentile of -0.102 to 0.315 ). Because zero is contained in the interval, not significantly, we concluded that positive and completely mediating effects for GOI between OCBE and GPDP. In addition, partial mediating effects for OCBE between GSV and GPDP.

Table 6. The mediation results of OCBE by using Confidence Interval Bootstrap.

\begin{tabular}{|c|c|c|c|c|c|c|c|}
\hline & \multirow{3}{*}{ Point Estimation } & \multirow{2}{*}{\multicolumn{2}{|c|}{ Product of Coefficients }} & \multicolumn{4}{|c|}{ Bootstrapping } \\
\hline & & & & \multicolumn{2}{|c|}{ Bias-Corrected $95 \%$ CI } & \multicolumn{2}{|c|}{ Percentile $95 \%$ CI } \\
\hline & & S.E. & $\mathbf{Z}$ & Lower & Upper & Lower & Upper \\
\hline \multicolumn{8}{|c|}{ Standardized Total Effect } \\
\hline GOI -> GPDP & 0.319 & 0.063 & $5.063 * * *$ & 0.201 & 0.444 & 0.204 & 0.449 \\
\hline GSV -> GPDP & 0.629 & 0.059 & $10.661^{* * *}$ & 0.503 & 0.734 & 0.505 & 0.736 \\
\hline \multicolumn{8}{|c|}{ Standardized Indirect Effect } \\
\hline GOI -> GPDP & 0.207 & 0.079 & $2.62 * *$ & 0.075 & 0.393 & 0.068 & 0.378 \\
\hline GSV -> GPDP & 0.141 & 0.042 & $23.8^{* * *}$ & 0.067 & 0.236 & 0.052 & 0.219 \\
\hline \multicolumn{8}{|c|}{ Standardized Direct Effect } \\
\hline GOI -> GPDP & 0.113 & 0.107 & 1.06 & -0.114 & 0.303 & -1.02 & 0.315 \\
\hline GSV $->$ GPDP & 0.488 & 0.084 & $5.81 * * *$ & 0.313 & 0.643 & 0.326 & 0.657 \\
\hline
\end{tabular}

\section{Conclusions and Implications}

The study had some research restrictions. First, the unexpected result indicates that the relations among the GOI, GSV, and GPDP were mediated by the OCBE. Therefore, the mediation role of OCBE needs to be verified by collecting related research in the future. Second, the samples were all selected from Taiwanese manufacturing companies. However, differences were observed in terms of national conditions, cultures, industries, and economic structures. Third, most companies were unlisted, which may have different norms than listed companies. Finally, this study explored the performance of GPD from the perspective of the internal environment of the organization and excluded external environmental factors.

This research was conducted to understand the previously unexplored relationship between the GOI and OCBE, which is particularly pertinent in this environmentally aware era. In this study, a research framework was proposed that focused on the effect of GOI and GSV on GPDP through the OCBE. This study empirically exhibited a positive correlation of GOI and GSV and on OCBE and GPDP. The findings were as follows: (1) Positive effects for GOI and GSV between OCBE and GPDP and (2) Positive effects of OCBE for GPDP. The results further indicate that the relations among the GOI, GSV, and GPDP were partially mediated by the OCBE; the results point that the OCBE acts as mediator between GOI, GSV and GPDP. After further examining the collecting data, we found (3) the relationship between GOI and GPDP is completely mediated by OCBE and (4) the relationship between 
GSV and GPDP is partially mediated by OCBE. When an organization substantially increases the inclination of its staff members toward identifying with its green organization and GSV, the company can stimulate OCBE, thereby facilitating successful GPDP. In addition, OCBE mediates GOI and GPDP in organizations and the relationship between GSV and GPDP. Therefore, organizations must strive to cultivate GOI and GSV for encouraging OCBE and stimulate GPDP.

The proposed study makes four academic contributions to the literature.

First, consistent with previous research that highlights the relation between the GOI and GSV for green creativity or green innovation [14,54]. The study contributes to this knowledge by incorporating additional variables, such as OCBE and GPDP as a mediator and response variable, respectively.

Second, a gap was observed in the previous research, which in a limited way revealed that the GOI and GSV have significant effect on green creativity. Studies did not account for GPDP. Thus, to address this gap, this study indicated that organization identity and GSV have significant effects on GPDP.

The third contribution is that this study indicates that green organizational citizenship behavior plays a crucial intermediary role between the GOI and GPDP and between GSV and GPDP. This observation highlights the catalytic role of OCBE of staff members on developing GPs.

The fourth and final contribution of this study indicates that the GOI and GSV have significantly different effects on the development of GPs. Therefore, organizations must strengthen the GOI and GSV to model the organizational citizenship behavior of staff members for the environment and to improve GPD.

The findings of this study suggest four practices for GPD.

First, GOI and GSV are crucial for OCBE and GPDP. If a company wants to enhance OCBE and GPDP, setting objectives, measures, and strategies for cultivating the GOI and GSV among the staff members is essential. Similarly, as organizations intend to profit from GPs, they must actively invest in formulating green policies, strengthening the GOI of staff members, and establishing an organization culture of GSV. For instance, the company must actively allocate budgeted resources or related policies, create an environment-friendly culture, encourage employee OCBE for enhancing GPDP of the organization, and create and maintain a competitive position in the market. Organizations can design relevant strategies and redesign their work processes by using several means, such as energy conservation and resource recovery [89], thus leveraging the GOI and GSV culture to transform the market and increase competitiveness. The deployment of these strategies in a novel form of environmental governance can fuel sustainable development, and combining this governance with the GOI and GSV culture can further facilitate effective GPD.

Second, because of the centrality of GOI and GSV practice includes adopting concrete methods to foster the GOI and green vision for reinforcing and promoting the citizenship behavior of staff members for the environment. Examples of implementing green and environment-friendly strategies include saving energy and reducing carbon emissions, reusing resources, and offering green creativity training courses designed according to the green culture of the organizations.

Third, since OCBE catalyzes GOI and green vision for successful GPD, OCBE must be highlighted. Thus, the organization can enact various management measures, such as a declaration on green environment and development of the organization, a green environment and development blueprint of the organization, and an incentive scheme to increase OCBE among staff members.

The fourth and final recommendation is that enterprises must actively bolster the GOI and GSV among staff members, train and educate them on OCBE in a corporate environment, and promote the successful development of GPs.

This study proposes eight directions for future research. First, the result of the research points that OCBE plays a mediation role between GOI, GSV, and GPDP. Therefore, the mediation role of OCBE needs to be verified by collecting related research in the future. Second, the model of this study is a discussion of the development performance of GPs. It considers the internal environment of the organization: the green common vision and green organization identification as prevariables. 
However, other possible influencing factors can be observed, and future researchers may explore the variables that are affected by the external environment of the organization or the related literature. Third, multiple analyses can be conducted to explore the benefits of the proposed research framework. Fourth, cross-country Chinese studies can be conducted, and the differences in their effects can then be explored. Fifth, future research may employ metrics to measure human resources, leadership style, and other psychological factors, which are not included in this study. Sixth, future research can further incorporate organizational characteristics or negative variables (e.g., overpackaging and greenwash) into the difference analyses, which was not included in the study. Seventh, the correlations of demographic variables include gender, marital status, and working experience on staff members in the organization can be further explored. Finally, future work can be conducted using model validation experiments.

Author Contributions: T.-W.C. proposed the research framework, ideas and analyzed the results. F.-F.C., H.-D.L. and Y.-S.C. wrote the paper in English.

Funding: The authors are grateful for the funding of Ministry of Science and Technology in Taiwan for this study, and the project number of this study is MOST 107-2410-H-606-002.

Conflicts of Interest: The authors declare no conflict of interest.

\section{References}

1. Chen, Y.S.; Chang, C.H.; Lin, Y.H. The Determinants of green radical and incremental innovation performance: Green shared vision, green absorptive capacity, and green organizational ambidexterity. Sustainability 2014, 6, 7787-7806. [CrossRef]

2. Chuang, S.P.; Huang, S.J. The effect of environmental corporate social responsibility on environmental performance and business competitiveness: The mediation of green information technology capital. J. Bus. Ethics 2018, 150, 991-1009. [CrossRef]

3. Shrivastava, P. Environmental technologies and competitive advantage. Strateg. Manag. J. 1995, 16, 183-200. [CrossRef]

4. Porter, M.E.; Van der Linde, C. Green and competitive: Ending the stalemate. J. Bus. Adm. Policy Anal. 1999, 73, 215-229.

5. Chen, Y.S. The positive effect of green intellectual capital on competitive advantages of firms. J. Bus. Ethics 2008, 77, 271-286. [CrossRef]

6. Chuang, S.P.; Huang, S.J. Effects of business greening and green IT capital on business competitiveness. J. Bus. Ethics 2015, 128, 221-231. [CrossRef]

7. Devi, N.C.; Maulida, G.A.; Perdana, B.P.; NA, M.A.; Hendrawan, R. The Impact of Commercial Development of the Reservation Environment in the German Investigation. ESE Int. J. Environ. Sci. Eng. 2018, 1, 21-24.

8. Berry, M.A.; Rondinelli, D.A. Proactive corporate environmental: A new industrial revolution. Acad. Manag. Exec. 1998, 12, 38-50. [CrossRef]

9. Angell, L.C.; Klassen, R.D. Integrating environmental issues into the mainstream: An agenda for research in operations management. J. Oper. Manag. 1999, 17, 575-598. [CrossRef]

10. Chen, Y.S. Green organizational identity: Sources and consequence. Manag. Decis. 2011, 49, 384-404. [CrossRef]

11. Welford, R. Corporate Environmental Management: Systems and Strategies; Routledge: London, UK, 2016; Volume 1.

12. Sezen, B.; Çankaya, S.Y. Green Supply Chain Management Theory and Practices. In Operations and Service Management: Concepts, Methodologies, Tools, and Applications; IGI Global: Hershey, PA, USA, 2018.

13. Krause, D. Environmental Consciousness: An Empirical Study. J. Environ. Behav. 1993, 25, 126-142. [CrossRef]

14. Chen, Y.S.; Chang, C.H.; Yeh, S.L.; Cheng, H.I. Green shared vision and green creativity: The mediation roles of green mindfulness and green self-efficacy. Qual. Quant. 2015, 49, 1169-1184. [CrossRef]

15. Chen, Y.S.; Lin, C.Y.; Weng, C.S. The influence of environmental friendliness on green trust: The mediation effects of green satisfaction and green perceived quality. Sustainability 2015, 7, 10135-10152. [CrossRef]

16. Chen, Y.-S. The Drivers of Green Brand Equity: Green Brand Image, Green Satisfaction, and Green Trust. J. Bus. Ethics 2010, 93, 307-319. [CrossRef] 
17. Dangelico, R.M. Improving firm environmental performance and reputation: The role of employee green teams. Bus. Strategy Environ. 2015, 24, 735-749. [CrossRef]

18. Dangelico, R.M. What Drives Green Product Development and How do Different Antecedents Affect Market Performance? A Survey of Italian Companies with Eco-Labels. Bus. Strategy Environ. 2017, 26, 1144-1161. [CrossRef]

19. Chen, Y.S.; Chang, C.H. The determinants of green product development performance: Green dynamic capabilities, green transformational leadership, and green creativity. J. Bus. Ethics 2013, 116, 107-119. [CrossRef]

20. Tian, Z.P.; Wang, J.; Wang, J.Q.; Zhang, H.Y. Simplified neutrosophic linguistic multi-criteria group decision-making approach to green product development. Group Decis. Negotiat. 2017, 26, 597-627. [CrossRef]

21. Zhou, S.; Zhang, D.; Lyu, C.; Zhang, H. Does Seeing “Mind Acts Upon Mind” Affect Green Psychological Climate and Green Product Development Performance? The Role of Matching Between Green Transformational Leadership and Individual Green Values. Sustainability 2018, 10, 3206. [CrossRef]

22. Erkut, B. Product innovation and market shaping: Bridging the gap with cognitive evolutionary economics. Indraprastha J. Manag. 2016, 4, 3-24.

23. Hayek, F.A. The Sensory Order: An Inquiry into the Foundations of Theoretical Psychology; University of Chicago Press: Chicago, IL, USA, 1952.

24. Erkut, B.; Kaya, T. Knowledge Generation for Regional Competitive Advantage. In Proceedings of the 18th European Conference on Knowledge Management, Barcelona, Spain, 7-8 September 2017; Volume 1, pp. 310-317.

25. Daily, B.F.; Bishop, J.W.; Govindarajulu, N. A conceptual model for organizational citizenship behavior directed toward the environment. Bus. Soc. 2009, 48, 243-256. [CrossRef]

26. Andersson, L.; Bateman, T. Individual environmental initiative: Championing natural environmental issues in U.S. Business Organizations. Acad. Manag. J. 2000, 43, 548-570.

27. Hanna, M.D.; Newman, W.R.; Johnson, P. Linking operational and environmental improvement through employee involvement. Int. J. Oper. Prod. Manag. 2000, 30, 148-165. [CrossRef]

28. Ramus, C.A. Organizing support for employees: Encouraging creative ideas for environmental sustainability. Calif. Manag. Rev. 2001, 43, 85-103. [CrossRef]

29. Ramus, C.A.; Killmer, A.B. Corporate greening through prosocial extrarole behaviours-A conceptual framework for employee motivation. Bus. Strategy Environ. 2007, 16, 554-570. [CrossRef]

30. Walley, L.; Stubbs, M. Termites and champions: Case comparisons by metaphor. Green. Manag. Int. 2000, 29, 41-54. [CrossRef]

31. Paillé, P.; Boiral, O.; Chen, Y. Linking environmental management practices and organizational citizenship behaviour for the environment: A social exchange perspective. Int. J. Hum. Resour. Manag. 2013, 24, 3552-3575. [CrossRef]

32. Boiral, O. Greening the corporation through organizational citizenship behaviors. J. Bus. Ethics 2009, 87, 221-236. [CrossRef]

33. Albino, V.; Balice, A.; Dangelico, R.M. Environmental strategies and green product development: An overview on sustainability-driven companies. Bus. Strategy Environ. 2009, 18, 83-96. [CrossRef]

34. Cronin, J.J.; Smith, J.S.; Gleim, M.R.; Ramirez, E.; Martinez, J.D. Green marketing strategies: An examination of stakeholders and the opportunities they present. J. Acad. Mark. Sci. 2011, 39, 158-174. [CrossRef]

35. Famiyeh, S.; Adaku, E.; Amoako-Gyampah, K.; Asante-Darko, D.; Amoatey, C.T. Environmental management practices, operational competitiveness and environmental performance: Empirical evidence from a developing country. J. Manuf. Technol. Manag. 2018, 29, 588-607. [CrossRef]

36. Maxfield, S. Reconciling corporate citizenship and competitive strategy: Insights from economic theory. J. Bus. Ethics 2008, 80, 367-377. [CrossRef]

37. Albert, S.; Whetten, D.A. Research in Organizational Behavior; JAI Press: Greenwich, CT, USA, 1985.

38. Dutton, J.E.; Dukerich, J.M. Keeping an eye on the mirror: Image and identity in organizational adaptation. Acad. Manag. J. 1991, 34, 517-554.

39. Foreman, P.; Whetten, D.A. Members' identification with multiple-identity organization. Organ. Sci. 2002, 13, 618-635. [CrossRef]

40. Gioia, D.A.; Thomas, J.B. Identity, image and issue interpretation: Sensemaking during strategic change in academia. Adm. Sci. Q. 1996, 41, 370-403. [CrossRef] 
41. Geraie, M.S.; Rad, F.M. Mediator Role of the Organizational Identity Green in Relationship between Total Quality Management and Perceived Innovation with Sustainable Competitive Advantage. Int. J. Biol. Pharm. Allied Sci. 2015, 4, 266-276.

42. Sharma, S. Managerial interpretations and organizational context as predictors of corporate choice of environmental strategy. Acad. Manag. J. 2000, 43, 681-697.

43. Feather, N.T.; Rauter, K.A. Organizational citizenship behaviours in relation to job status, job insecurity, organizational commitment and identification, job satisfaction and work values. J. Occup. Organ. Psychol. 2004, 77, 81-94. [CrossRef]

44. Lee, E.S.; Park, T.Y.; Koo, B. Identifying organizational identification as a basis for attitudes and behaviors: A meta-analytic review. Psychol. Bull. 2015, 141, 1049-1080. [CrossRef]

45. Christ, O.; Van Dick, R.; Wagner, U.; Stellmacher, J. When teachers go the extra mile: Foci of organisational identification as determinants of different forms of organisational citizenship behaviour among schoolteachers. Br. J. Educ. Psychol. 2003, 73, 329-341. [CrossRef]

46. Newman, A.; Miao, Q.; Hofman, P.S.; Zhu, C.J. The impact of socially responsible human resource management on employees' organizational citizenship behaviour: The mediating role of organizational identification. Int. J. Hum. Resour. Manag. 2016, 27, 440-455. [CrossRef]

47. Shim, D.C.; Faerman, S. Government employees' organizational citizenship behavior: The impacts of public service motivation, organizational identification, and subjective OCB norms. Int. Public Manag. J. 2017, 20, 531-559. [CrossRef]

48. Yu, H.Y.; Lou, J.H.; Eng, C.J.; Yang, C.I.; Lee, L.H. Organizational citizenship behaviour of men in nursing professions: Career stage perspectives. Collegian 2018, 25, 19-26. [CrossRef]

49. Erkut, B. The Emergence of the ERP Software Market between Product Innovation and Market Shaping. Journal of Open Innovation: Technology. Mark. Complex. 2018, 4, 23-43.

50. Witt, U. Competition as an Ambiguous Discovery Procedure: A Reappraisal of F. A. Hayek's Epistemic Liberalism. Econ. Philos 2013, 29, 121-138. [CrossRef]

51. Ashforth, B.E.; Mael, F. Social identity theory and the organization. Acad. Manag. Rev. 1989, 14, 20-39. [CrossRef]

52. Van Knippenberg, D.; Van Schie, E.C.M. Foci and correlates of organizational identification. J. Organ. Psychol. 2000, 79, 137-147. [CrossRef]

53. Cheney, G. On the various and changing meaning of organizational membership: A field study of organizational identification. Commun. Monogr. 1983, 50, 342-362. [CrossRef]

54. Chang, C.H.; Chen, Y.S. Green organizational identity and green innovation. Manag. Decis. 2013, 51, 1056-1070. [CrossRef]

55. Fishbein, M.; Ajzen, I. Belief, Attitude, Intention and Behavior: An Introduction to Theory and Research; Addison Wesley: Reading, MA, USA, 1975.

56. Chang, C.H. The determinants of green product innovation performance. Corp. Soc. Responsib. Environ. Manag. 2016, 23, 65-76. [CrossRef]

57. Song, W.; Yu, H. Green Innovation Strategy and Green Innovation: The Roles of Green Creativity and Green Organizational Identity. Corp. Soc. Responsib. Environ. Manag. 2018, 25, 135-150. [CrossRef]

58. Brown, S.L.; Eisenhardt, K.M. Product development: Past research, present findings, and future directions. Acad. Manag. Rev. 1995, 20, 343-378. [CrossRef]

59. Krishnan, V.; Ulrich, K.T. Product development decisions: A review of the literature. Manag. Sci. 2001, 47, 1-21. [CrossRef]

60. Dougherty, D. Understanding new markets for new products. Strateg. Manag. J. 1990, 11, 59-78.

61. Bass, B.M. From transactional to transformational leadership: Learning to share the vision. Organ. Dyn. 1991, 18, 19-31. [CrossRef]

62. Rice, M.P.; O'Connor, G.C.; Peters, L.S.; Morone, J.G. Managing discontinuous innovation. Res. Technol. Manag. 1998, 41, 52-58. [CrossRef]

63. Mackie, D.M.; Goethals, G.R. Individual and Group Goals; Prentice Hall: New York, NY, USA, 1987.

64. Jansen, J.J.; George, G.; Van den Bosch, F.A.; Volberda, H.W. Senior team attributes and organizational ambidexterity: The moderating role of transformational leadership. J. Manag. Stud. 2008, 45, 982-1007. [CrossRef]

65. Giordan, J.C. "That Vision Thing" the Key to Sustainable Competitive Advantage. Res. Technol. Manag. 1995, 38, 8-22. [CrossRef] 
66. Vogus, T.J.; Sutcliffe, K.M. Organizational mindfulness and mindful organizing: A reconciliation and path forward. Acad. Manag. Learn. Educ. 2012, 11, 722-735. [CrossRef]

67. Sosik, J.J.; Kahai, S.S.; Avolio, B.J. Transformational leadership and dimensions of creativity: Motivating idea generation in computer-mediated groups. Creat. Res. J. 1998, 11, 111-121. [CrossRef]

68. Katz, D.; Kahn, R.L. The Social Psychology of Organizations; Wiley: New York, NY, USA, 1978.

69. MacKenzie, S.B.; Podsakoff, P.M.; Rich, G.A. Transformational and transactional leadership and salesperson performance. J. Acad. Mark. Sci. 2001, 29, 115-134. [CrossRef]

70. Larwood, L.; Falbe, C.M.; Kriger, M.P.; Miesing, P. Structure and meaning of organizational vision. Acad. Manag. J. 1995, 38, 740-769.

71. Ayag, Z. An integrated approach to evaluating conceptual design alternatives in a new product development environment. Int. J. Prod. Res. 2005, 43, 687-713. [CrossRef]

72. Fitzsimmons, J.A.; Kouvelis, P.; Mallick, D.N. Design strategy and its interface with manufacturing and marketing: A conceptual framework. J. Oper. Manag. 1991, 10, 398-415. [CrossRef]

73. Orsato, R.J. Competitive environmental strategies: When does it pay to be green? Calif. Manag. Rev. 2006, 48, 127-143. [CrossRef]

74. Park, R. The roles of OCB and automation in the relationship between job autonomy and organizational performance: A moderated mediation model. Int. J. Hum. Resour. Manag. 2016, 27, 1-18. [CrossRef]

75. Mesmer-Magnus, J.R.; Asencio, R.; Seely, P.W.; DeChurch, L.A. How organizational identity affects team functioning: The identity instrumentality hypothesis. J. Manag. 2018, 44, 1530-1550. [CrossRef]

76. Newton, D.W.; LePine, J.A. Organizational Citizenship Behavior and Job Engagement: “You Gotta Keep'em Separated!". In Oxford Handbook of Organizational Citizenship Behavior; Oxford University Press: Oxford, UK, 2018; pp. 43-54.

77. Boiral, O.; Paillé, P. Organizational citizenship behaviour for the environment: Measurement and validation. J. Bus. Ethics 2012, 109, 431-445. [CrossRef]

78. Hart, S. A natural-resource-based view of the firm. Acad. Manag. Rev. 1995, 20, 986-1014. [CrossRef]

79. Ramus, C.A.; Steger, U. The roles of supervisory support behaviors and environmental policy in employee Eco-initiatives at leading-edge European companies. Acad. Manag. J. 2000, 43, 605-626.

80. Florida, R.L. Lean and green: The move to environmentally conscious manufacturing. Calif. Manag. Rev. 1996, 39, 80-105. [CrossRef]

81. Roy, M.J.; Boiral, O.; Lagace', D. Environmental commitment and manufacturing excellence: A comparative study within Canadian industry. Bus. Strategy Environ. 2001, 10, 257-268. [CrossRef]

82. Podsakoff, P.M.; Organ, D.W. Self-reports in organizational research: Problems and prospects. J. Manag. 1986, 12, 531-544. [CrossRef]

83. Podsakoff, P.M.; MacKenzie, S.B.; Lee, J.Y.; Podsakoff, N.P. Common method biases in behavioral research: A critical review of the literature and recommended remedies. J. Appl. Psychol. 2003, 88, 879-903. [CrossRef] [PubMed]

84. Paillé, P.; Chen, Y.; Boiral, O.; Jin, J. The impact of human resource management on environmental performance: An employee-level study. J. Bus. Ethics 2014, 121, 451-466. [CrossRef]

85. Hair, J.F.; Anderson, R.E.; Tatham, R.L.; Black, W.C. Multivariate Data Analysis; Prentice-Hall, Inc.: Upper Saddle River, NJ, USA, 1998.

86. Fornell, C.; Larcker, D.F. Structural equation models with unobservable variables and measurement error: Algebra and statistics. J. Mark. Res. 1981, 18, 382-388. [CrossRef]

87. Baron, R.M.; Kenny, D.A. The moderator-mediator variable distinction in social psychological research: Conceptual, strategic, and statistical considerations. J. Personal. Soc. Psychol. 1986, 51, 1173-1182. [CrossRef]

88. Taylor, A.B.; MacKinnon, D.P.; Tein, J.Y. Tests of the three-path mediated effect. Organ. Res. Methods 2008, 11, 241-269. [CrossRef]

89. Ioppolo, G.; Cucurachi, S.; Salomone, R.; Saija, G.; Shi, L. Sustainable local development and environmental governance: A strategic planning experience. Sustainability 2016, 8, 180-195. [CrossRef]

(C) 2019 by the authors. Licensee MDPI, Basel, Switzerland. This article is an open access article distributed under the terms and conditions of the Creative Commons Attribution (CC BY) license (http:// creativecommons.org/licenses/by/4.0/). 